OPEN

SUBJECT AREAS:

PROTEIN TRANSPORT

ENVIRONMENTAL BIOTECHNOLOGY

TRANSPORTERS

PROTEIN TRANSPORT

Received

22 July 2013

Accepted

15 November 2013

Published

5 December 2013

Correspondence and requests for materials should be addressed to

M.B. (Mahchid.

Bamdad@udamail.fr)

* Current address: EA 4677 ERTICa : Equipe de Recherche sur les Traitements

Individualisés des

Cancers - Site IUT, Institut Universitaire de

Technologie de

Clermont-Fd -

Université d'Auvergne,

Département Génie

Biologique, Complexe

Universitaire des

Cézeaux, B.P. 86,

63172 Aubière

Cedex.

\section{P-gp expression in brown trout erythrocytes: evidence of a detoxification mechanism in fish erythrocytes}

\author{
Emeline Valton 1,2,3, Christian Amblard ${ }^{3}$, Ivan Wawrzyniak ${ }^{3}$, Frederique Penault-Llorca ${ }^{1,2}$ \\ \& Mahchid Bamdad ${ }^{1,2,3 *}$
}

'Clermont Université - Université d'Auvergne - ERTICa- EA 4677 - Institut Universitaire de Technologie, département génie biologique, Ensemble universitaire des Cézeaux, B.P. 86 - 63172 AUBIERE CEDEX France, ${ }^{2}$ Clermont Université - Université d'Auvergne ERTICa - EA 4677- Centre Jean Perrin, 58 Rue Montalembert, BP 392 - 63011 CLERMONT-FERRAND CEDEX France, ${ }^{3}$ Clermont Université - Université Blaise Pascal - LMGE - UMR CNRS 6023 - BP 80026- 63171 AUBIERE CEDEX France.

Blood is a site of physiological transport for a great variety of molecules, including xenobiotics. Blood cells in aquatic vertebrates, such as fish, are directly exposed to aquatic pollution. P-gp are ubiquitous "membrane detoxification proteins" implicated in the cellular efflux of various xenobiotics, such as polycyclic aromatic hydrocarbons (PAHs), which may be pollutants. The existence of this P-gp detoxification system inducible by benzo [a] pyrene (BaP), a highly cytotoxic $\mathrm{PAH}$, was investigated in the nucleated erythrocytes of brown trout. Western blot analysis showed the expression of a $140-\mathrm{kDa}$ P-gp in trout erythrocytes. Primary cultures of erythrocytes exposed to increasing concentrations of $\mathrm{BaP}$ showed no evidence of cell toxicity. Yet, in the same $\mathrm{BaP}$-treated erythrocytes, $\mathrm{P}$-gp expression increased significantly in a dose-dependent manner. Brown trout $\mathrm{P}$-gp erythrocytes act as membrane defence mechanism against the pollutant, a property that can be exploited for future biomarker development to monitor water quality.

T he bloodstream is a hub for the transport and inter-reaction of a variety of physiological molecules (oxygen, nutrients, hormones and waste) and also for the accumulation of xenobiotics (drugs and/or pollutants). Whatever the type of pollution (acute or chronic), the various pollutants are either found directly in the blood or accumulated in organs, tissues and cells before being gradually released into the circulation. Erythrocytes are the major cellular component of blood. In mammals, including man, mature erythrocytes are not nucleated, unlike fish, where they are ${ }^{1}$. Among fish, Salmonids are integrative organisms with regard to environmental conditions and water quality. They are "bioaccumulation" organisms ${ }^{2}$. Brown trout (Salmo trutta fario) provide a ubiquitous and highly sensitive index of water quality. Furthermore, the brown trout is not only native to rivers but may also be fish-farmed.

P-gp, the well-known "Multidrug Resistance" (MDR) protein encoded by the MDR1 or ABCB1 gene, have been described as membrane transporters involved in resistance to chemotherapy in cancer ${ }^{3}$. In reality, P-gp belongs to the evolutionarily conserved family of the ATP-binding cassette $(\mathrm{ABC})$ proteins found in practically all living organisms, whether prokaryotic ${ }^{4}$ or eukaryotic ${ }^{3,5-13}$. P-gp acts as xenobiotics efflux pump transporting various substrates out of cells. It recognizes various molecules with different structures and properties, including pollutants such as polycyclic aromatic hydrocarbons (PAHs) (e.g. benzo-a-pyrene (BaP)), heavy metals (e.g. cadmium), pesticides (e.g. diazinon, DDT), insecticides (e.g. chlorpyrifos) and various pharmaceutical drugs, such as chemotherapeutic drugs (e.g. Vinca alkaloids, actinomycin D, taxol, antracyclines), calcium channel blockers (e.g. verapamil) ${ }^{3,5,6,11,12,14-22}$. Due to this property, P-gp is involved in the natural defence mechanisms of cells, tissues and organs, and forms an essential part of the innate defence system known as "chemo-immunity".

Our previous research in both laboratory and field has focused on the development of environmental biomarkers for $\mathrm{PAH}$ pollution based on MDR1/P-gp expression, using the freshwater ciliated protozoan Tetrahymena pyriformis for water pollution and the vinegar fly Drosophila melanogaster for air pollution. In these two models, P-gp expression was clearly induced in a dose-dependent manner, after exposure to different concentrations of various classes of $\mathrm{PAHs}^{5,6,11,12}$.

In the present work, we aimed to analyze P-gp expression in the erythrocytes of brown trout and their response to $\mathrm{B} a \mathrm{P}$, a PAH model, in order to develop an aquatic biomarker. 
a

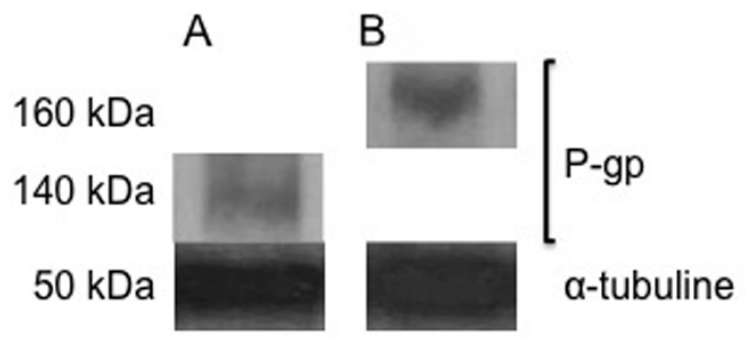

b
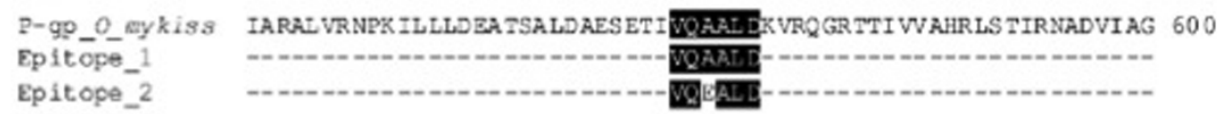

Figure $1 \mid$ P-gp expression in brown trout erythrocytes. (a). Western blot analysis of P-gp in brown trout: P-gp protein was analyzed in total protein extract from (A) a dry pellet of brown trout erythrocytes or (B) liver. P-gp weighed $140 \mathrm{kDa}$ in A and $160 \mathrm{kDa}$ in B. The monoclonal anti-tubulin antibody DM1A labelled a tubulin protein presented a molecular weight of about $50 \mathrm{kDa}$, used as internal control. The samples derive from the same experiment and gels were processed in parallel. The full-length blot and Coomassie blue gel are presented in Supplementary Figures 1a and 1b. (b). Sequence alignment of Oncorhynchus mykiss P-gp with the two different epitopes (VQAALD and VQEALD) recognized by C219 antibody. The alignment was performed using ClustalW. Conserved residues and similar residues are shaded in black and grey, respectively.

\section{Results}

Expression of P-gp in brown trout erythrocytes. The expression of P-gp in erythrocytes was analyzed from a dry pellet of brown trout erythrocytes by Western blotting (Fig. 1, and Supplementary Fig. 1a, and $\mathrm{b}$ ). The results showed that the monoclonal anti-P-gp antibody C219 clearly recognized a protein having a molecular weight (MW) of $140 \mathrm{kDa}$ (Fig. 1a). As expected, in the brown trout liver extract used as the positive control, a P-gp of $160 \mathrm{kDa}$ was labelled ${ }^{23}$. A second band of about $75 \mathrm{kDa}$ was also labelled by C219 antibody in trout erythrocytes. Moreover, the sequence alignment of rainbow trout Pgp available in Genbank with the "VQEALD" and "VQAALD" epitopes was recognized by $\mathrm{C} 219$ antibody ${ }^{24}$ was then checked via CLUSTALW. The results confirmed that the VQAALD epitope, recognized by $\mathrm{C} 219$ monoclonal antibody, was present in trout Pgp (Fig. 1b). The expression of P-gp in the brown trout erythrocytes quantified under these conditions was $0.84 \pm 0.05$ a.u.

Development of primary culture of brown trout erythrocytes. For the development of primary culture of erythrocytes, three culture media were used: i.e. IMDM, MEM and L-15, supplemented with $10 \%$ fetal calf serum, $1 \%$ penicillin/streptomycin, $1 \%$ fungizone and $1 \% \mathrm{~L}$-glutamine, under different temperature conditions $\left(11^{\circ} \mathrm{C}\right.$, $15^{\circ} \mathrm{C}, 18^{\circ} \mathrm{C}$ or $21^{\circ} \mathrm{C}$ ) with or without shaking. One million cells per $\mathrm{mL}$ were seeded in each medium, and the rate of cell growth was assessed over time. For the three culture media tested, the best temperature and stirring conditions for maintaining trout erythrocytes in primary culture were $21^{\circ} \mathrm{C}$ and $45 \mathrm{rpm}$ (data not shown). These conditions were thus used to track erythrocyte growth rates in the three tested media in both the short term $(24 \mathrm{~h})$ and longer term (5 days). The results presented in Figure 2 show that in all three media, cell growth rates remained relatively stable over $5 \mathrm{~h}$, i.e. the short term, with a yield close to 1 . In the longer term ( 1 to 5 days), the growth rate remained close to 1 in L-15 and IMDM media, but fell slightly in the MEM medium. These results suggest that L-15 and IMDM media may be used for the primary culture of brown trout erythrocytes. However, a comparison of cell morphology and cell membrane shape in primary cultures of L-15 and IMDM media showed that erythrocytes in the L-15 medium were less damaged and kept their cell membranes intact (data not shown). Thus, the L-15 medium was chosen for further experiments.

BaP toxicity analysis on trout erythrocytes. The toxicity of 10, 20 and $30 \mu \mathrm{M} \mathrm{BaP}$ on cultured trout erythrocytes was then studied, by cells counts over time using a Z-2 cell and particle counter. The rate of cell numbers was expressed as N/N0, where N and N0 are cell numbers at time $\mathrm{T}$ and $\mathrm{T} 0$ (beginning of experiment or after addition of $\mathrm{DMSO}$ or $\mathrm{B} a \mathrm{P})$. The results showed that in the presence of $\mathrm{B} a \mathrm{P}$ at 10,20 and $30 \mu \mathrm{M}$, the number of cells remained stable over time without signs of $\mathrm{B} a \mathrm{P}$ toxicity (Fig. 3).

P-gp expression in trout erythrocytes after treatment with benzo $[a]$ pyrene. Using Western blot analysis, the expression levels of P-gp in primary culture were measured for 3, 6 and $24 \mathrm{~h}$ in the presence of increasing concentrations of $\mathrm{B} a \mathrm{P}(10,20$ and $30 \mu \mathrm{M})$ (Fig. 4). Control cultures (untreated cells and in 0.1\% DMSO) were performed in parallel. P-gp expression levels in untreated cells and in

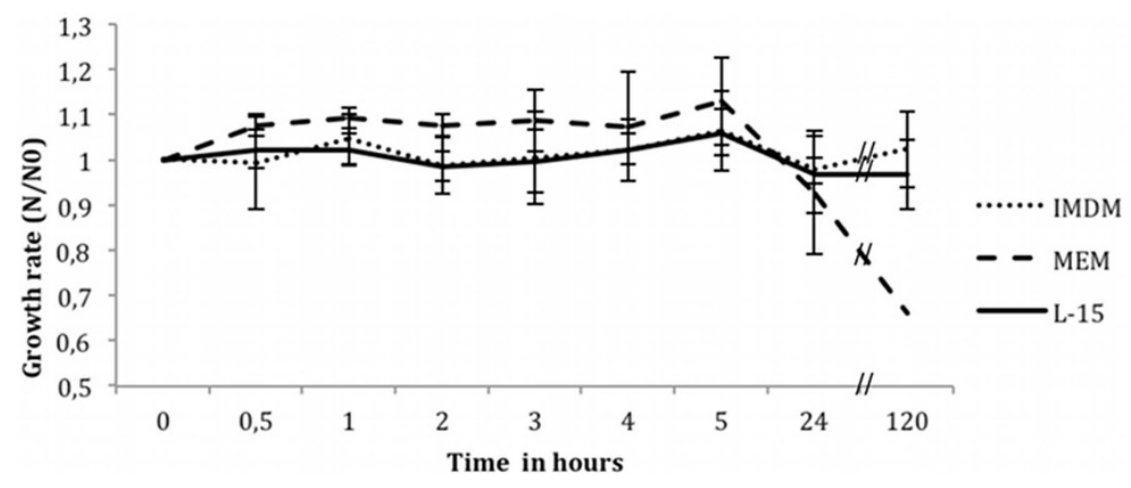

Figure $2 \mid$ Growth of brown trout erythrocytes in primary culture over time. Cells counts were followed over time using a Beckman Coulter Z-2 Counter. $\mathrm{N}$ : number of cells at time T. N0: number of cells at time T0 (beginning of experiment). 


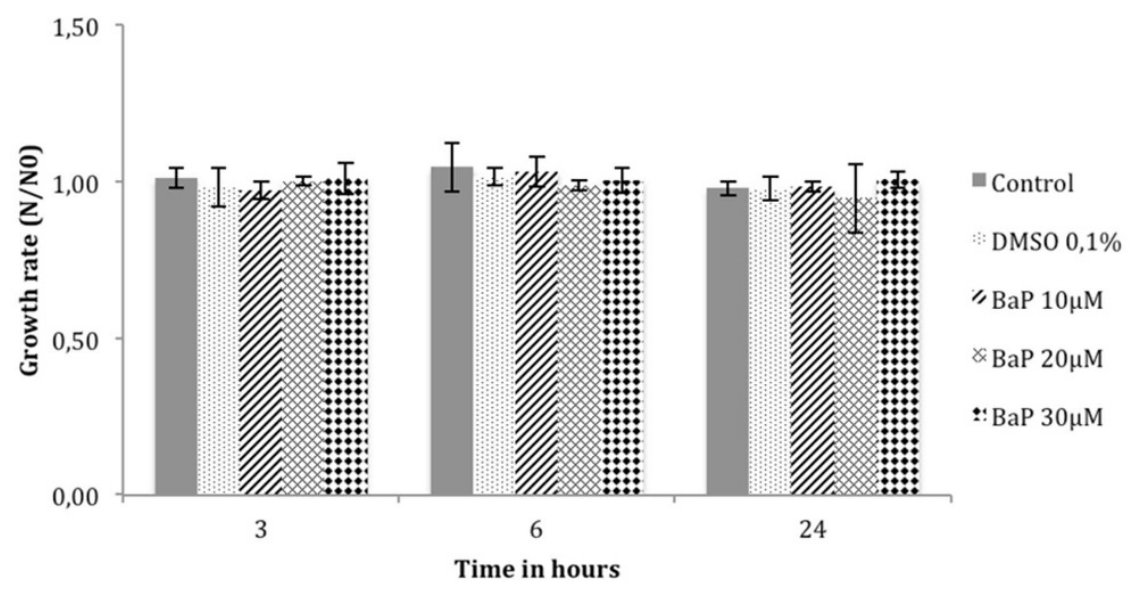

Figure $3 \mathrm{BaP}$ toxicity analysis on brown trout erythrocytes. Erythrocytes in primary culture were treated with 10,20 and $30 \mu \mathrm{M}$ of $\mathrm{B} a \mathrm{P}$ for 3,6 and $24 \mathrm{~h}$. Cell growth was analyzed by cell counting on the Beckman Coulter Z-2 Counter. N: number of cells at time T. N0: number of cells at time T0 (beginning of experiment).

$0.1 \%$ DMSO remained stable over $24 \mathrm{~h}(0.16 \pm 0.01$ and $0.19 \pm$ 0.06 a.u. at $24 \mathrm{~h}$, respectively). There was no significant difference between controls. 0.1\% DMSO had no effect on P-gp expression. The addition of $10 \mu \mathrm{M} \mathrm{BaP}$ to the cell cultures did not change the expression rate of $\mathrm{P}$-gp for $6 \mathrm{~h}$, which remained close to the control values $(0.12 \pm 0.02$ a.u.). In these cells, $\mathrm{P}$-gp rate only increased after $24 \mathrm{~h}$ of $\mathrm{B} a \mathrm{P}$ exposure $(0.41 \pm 0.05$ a.u. $)$. Conversely, in the presence of both 20 and $30 \mu \mathrm{M} \mathrm{BaP}, \mathrm{P}$-gp expression was clearly induced during the experiment. Indeed, in the presence of $20 \mu \mathrm{M} \mathrm{B} a \mathrm{P}, \mathrm{P}$ gp expression increased steadily over time to reach $0.44 \pm 0.1,0.55 \pm$ 0.1 and $0.70 \pm 0.1$ a.u. after 3,6 and $24 \mathrm{~h}$, respectively. In the presence of $30 \mu \mathrm{M} \mathrm{BaP}, \mathrm{P}$-gp remained high, at $0.65 \pm 0.01,0.42$ \pm 0.08 and $0.51 \pm 0.01$ a.u. after 3,6 and $24 \mathrm{~h}$, respectively.

\section{Discussion}

Blood delivers necessary substances such as nutrients and oxygen to cells and transports metabolic waste. Blood is also a site of passage and distribution of all xenobiotics (drugs and/or pollutants) which enter the organism. In aquatic vertebrates, such as fish, blood cells are directly exposed to the contamination. Therefore, they provide an excellent tool for water pollution detection.

In cells, P-gp is a ubiquitous membrane detoxification protein involved in the defence mechanisms against xenobiotics. It recognizes a large class of xenobiotics, from different drugs ${ }^{3}$ to various pollutants, such as $\mathrm{PAHs}^{5,6,11,12,25}$. The latter are highly ubiquitous environmental contaminants and include toxic compounds with cytotoxic, genotoxic and carcinogenic properties ${ }^{26-28}$. It has already been demonstrated that P-gp expression may be induced after exposure to PAHs in different cells models and/or organisms, suggesting that P-gp may be used as a potential biomarker of environmental pollution ${ }^{5,11,12,25,29}$.

In this context, our work focused on P-gp expression in erythrocytes using the Salmonidae brown trout as a model since it can live in most rivers. Firstly, P-gp expression was studied directly in dry pellets of cells using Western blot analysis. The monoclonal antibody anti-P-gp C219 clearly marked a protein of $140 \mathrm{kDa}$. As

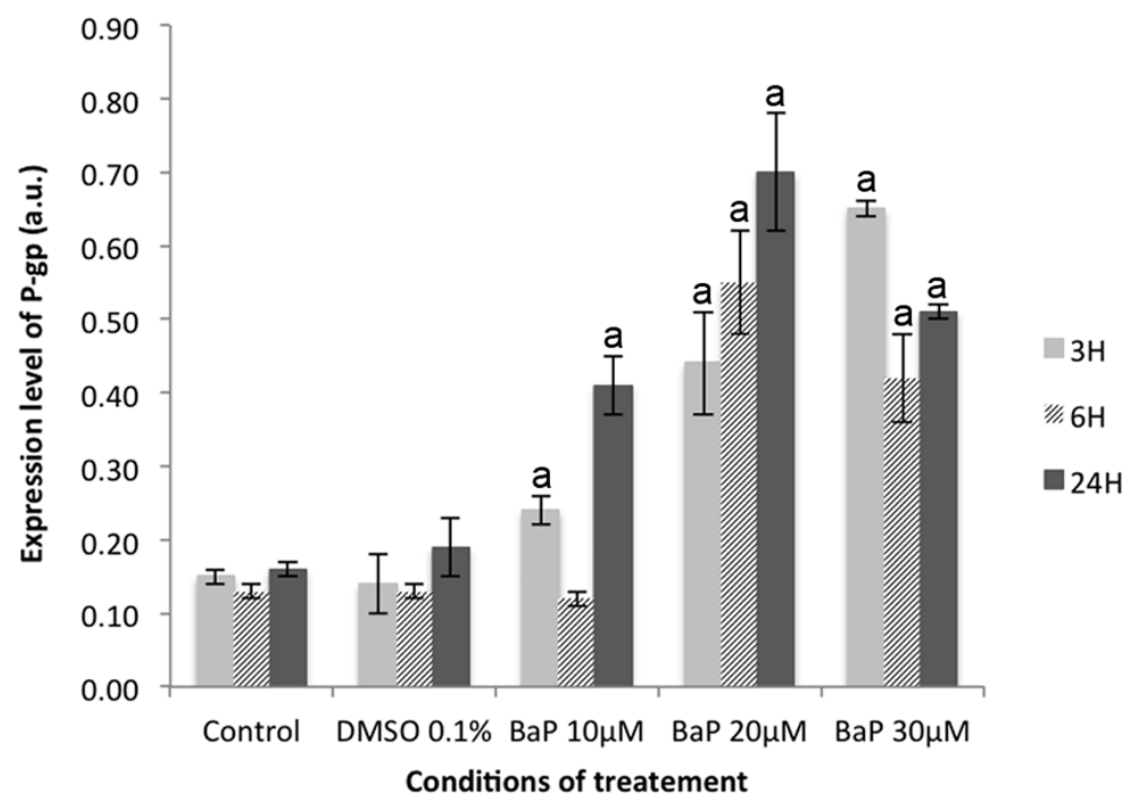

Figure $4 \mid \mathrm{P}$-gp expression in brown trout erythrocytes in the presence of BaP. Brown trout erythrocytes were exposed to 10,20 and $30 \mu \mathrm{M}$ of $\mathrm{B} a \mathrm{P}$. After $3 \mathrm{~h}, 6 \mathrm{~h}$ and $24 \mathrm{~h}$ of treatment, the cells were recovered to perform protein extraction. Following extraction, Western blotting was performed and protein expression quantified using Quantity One software (Biorad $\left.{ }^{\circledR}\right)$. Statistical analysis was performed by Student's t-test. "a" indicate a significant difference $(\mathrm{p}<0.05)$ in $\mathrm{P}$-gp expression between $\mathrm{B} a \mathrm{P}$ treated samples and controls. 
a P-gp-positive control we used brown trout liver extract with a molecular weight of about $160 \mathrm{kDa}$. Indeed, the expression of a $165 \mathrm{kDa}$ P-gp has been reported in liver extract and hepatocyte cell cultures of another trout species, Oncorhynchus mykiss ${ }^{23}$. Moreover, depending on species and tissue, the apparent molecular mass of Pgp may vary between 130 and $180 \mathrm{kDa}$, reflecting differences in glycosylation $^{30}$. The monoclonal C219 anti-P-gp recognized a P-gp of $170 \mathrm{kDa}$ in $\mathrm{man}^{3}$, and of $140 \mathrm{kDa}$ in Drosophila melanogaster ${ }^{11,12}$. In addition, depending on species, other P-gp molecular weights were also cited, such as a $55 \mathrm{kDa}$ P-gp in cattle ${ }^{31}$, a $66 \mathrm{kDa}$ and a $96 \mathrm{kDa}$ P-gp in the freshwater ciliated protozoan Tetrahymena pyriformis ${ }^{5}$. These results suggest that a P-gp of $140 \mathrm{kDa}$ was expressed in the nucleated erythrocytes of brown trout. Furthermore, the C219 monoclonal antibody seems to label another protein with a MW of $75 \mathrm{kDa}$ in trout erythrocytes. Previously, the labelling of an $80 \mathrm{kDa}$ band of unknown identity was also reported in trout liver and cultured hepatocytes by the same antibody ${ }^{10}$.

Secondly, for trout P-gp erythrocytes induction study, we developed the best set of conditions for in vitro culture, such as type of culture medium, cell density, temperature and stirring. The results showed that it was possible to achieve primary cultures of trout erythrocytes over time. Indeed, as trout erythrocytes are nucleated, it should be possible to maintain them in culture for several days. The best conditions for in vitro culture were Leibovitz's medium (L-15) supplemented with $10 \%$ fetal bovine serum, $1 \%$ penicillin/streptomycin, $1 \%$ fungizone and $1 \% \mathrm{~L}$-glutamine, at a temperature of $21^{\circ} \mathrm{C}$, with stirring at $45 \mathrm{rpm}$. The development of primary blood cell cultures in the trout model offers further scope for adaptation to other fish models or to species possessing nucleated erythrocytes. This in vitro culture model may be used for future cytotoxicity tests on various xenobiotics and/or for other applications linked tied to a fish health model. After starting red blood cell culture in vitro, it was necessary to analyze the response of P-gp to PAHs. For this purpose, we chose to test the action of $\mathrm{B} a \mathrm{P}$, which is a cytotoxic, genotoxic and carcinogenic model pollutant in the PAHs class. It has been found in air, water and soil ${ }^{32,33}$. Moreover, $\mathrm{B} a \mathrm{P}$, like several other PAHs, has been shown to induce P-gp in other biological models of aquatic and atmospheric pollution ${ }^{5,11,12}$. BaP toxicity at 10,20 and $30 \mu \mathrm{M}$ was first tested by analyzing red blood cell numbers in primary culture over time. No toxicity was detected at these concentrations, probably due to the detoxification action of P-gp in the erythrocytes. Similar responses have already been detected in the ciliated protozoan model Tetrahymena pyriformis and in SL2 Drosophila melanogaster cell culture in the presence of similar concentrations of $\mathrm{B} a \mathrm{P}$ and other $\mathrm{PAHs}^{5,12,21}$.

This hypothesis of detoxifying action by $\mathrm{P}$-gp was then checked by monitoring P-gp expression over time in primary cultures of erythrocytes, after treatment with increased concentration of $\mathrm{B} a \mathrm{P}$. Under these conditions, a clear dose-dependent induction of P-gp expression was detected in trout erythrocytes. With $10 \mu \mathrm{M} \mathrm{B} a \mathrm{P}, \mathrm{P}$ gp expression increased only after $24 \mathrm{~h}$ of treatment with a 2 -fold higher ratio than in the controls. The $\mathrm{P}$-gp induction was clearly noted with 20 and $30 \mu \mathrm{M} \mathrm{BaP}$ from $3 \mathrm{~h}$ to $24 \mathrm{~h}$, with a mean ratio 3.6-fold higher than controls. These results suggest that P-gp is involved in the mechanisms of cellular defence against $\mathrm{B} a \mathrm{P}$ pollutant. Similar findings have already been described in other models ${ }^{5,6,11,12}$.

All these results suggest that trout erythrocytes can be used to develop biomarkers to determine water pollution by PAHs. Indeed, such a development offers two lines of interest. First, the blood being a fluid tissue circulating throughout the body, this biomarker may reflect the overall state of fish contamination, with possible applications in the agri-food sector. It may also reflect the state of water contamination and thus have applications in the field of environmental monitoring. Experiments to develop a P-gp biomarker are currently being tested on brown trout in a natural environment.

\section{Methods}

Fish model and blood sampling. Brown trout (Salmo trutta fario) were obtained from the "Le Moulin de Pagnat" fish farm, Saint-Saturnin, France. For blood sampling, they were anesthetized using a mix of clove oil in $70 \%$ alcohol. Blood samples were then taken by intracardiac puncture onto lithium heparinate anticoagulant. $500 \mu \mathrm{L}$ of blood were then washed twice with $1 \mathrm{~mL}$ of PBS by centrifugation at $800 \mathrm{G}$ for 10 minutes and then the supernatant was removed. After centrifugation, red blood cells were concentrated in the lower portion of the tube and white blood cells, in the form of a thin layer, were seen on the surface of the layer of red blood cells. The fraction of white blood cells was removed. To achieve the primary culture, only the fraction of red blood cell pellets was used (Supplementary Fig. 2). Erythrocytes were counted using a Malassez cell counter. The cells were then used either immediately for primary cell culture or stored at $-20^{\circ} \mathrm{C}$ as dry pellets.

Ethics. In compliance with the European Directive 2010/63/UE and Decree No. 2013 118 of application of 1 February 2013 on the protection of animals used for scientific purposes ref NOR: AGRG12131951D - ethical approval was not required for this study since fish were anesthetized with an overdose of a natural anesthetic.

Red blood cell culture development. The red blood cell culture was achieved using three culture media: Iscove's Modified Dulbecco's Medium (IMDM), Minimum Essential Medium (MEM) and Leibovitz's medium (L-15) (Gibco ${ }^{\circledR}$, Invitrogen). Erythrocytes were seeded in 25 -ml flasks at one million cells per $\mathrm{mL}$ in each culture medium, enabling development of optimal culture conditions.

Cell counts. Cells in cultures were counted electronically using a Beckman Coulter ${ }^{\mathrm{TM}}$ Z-2 cell and particle counter. The results were expressed as N/N0, where N corresponded to cell number at time T and N0, to cell number at T0 (beginning of experiment or after addition of DMSO or $\mathrm{B} a \mathrm{P}$ ).

$\mathrm{B} a \mathrm{P}$ solubilization and exposure. $\mathrm{B} a \mathrm{P}$ was dissolved in dimethyl sulfoxide (DMSO) as a stock solution at $5 \mathrm{mM}$. For each experiment, one million cells $/ \mathrm{mL}$ were seeded in $10 \mathrm{~mL}$ of culture medium. The cell cultures were then exposed to concentrations of $10 \mu \mathrm{M}, 20 \mu \mathrm{M}$ and $30 \mu \mathrm{M} \mathrm{B} a \mathrm{P}$. For each $\mathrm{B} a \mathrm{P}$ concentration studied, the required volume of $\mathrm{B} a \mathrm{P}$ was removed from the $\mathrm{B} a \mathrm{P}$ stock solution. This was then supplemented with the appropriate volume of DMSO, so that the final DMSO concentration remained constant i.e. $0.1 \%$, in all analyzed cell cultures. In parallel, two control cultures were carried out: (i) untreated cells and (ii) primary culture of erythrocytes treated with $0.1 \%$ DMSO.

MDR expression studies by Western blot analysis. For each experiment (red blood cell pellets and primary cell cultures), the erythrocytes were collected by a centrifugation at $800 \mathrm{G}$ for $10 \mathrm{~min}$ at $4^{\circ} \mathrm{C}$. The cells were then treated with $1 \mathrm{ml}$ of lysis buffer ( 20 mM tris-HCl, 2 mM EDTA, 2 mM EGTA, $6 \mu \mathrm{M} \beta$-mercaptoethanol, and $0.1 \%$ protease inhibitor cocktail, $\mathrm{pH} 7.5$ ). For protein extraction, this sample was sonicated $\left(5 \times 5 \mathrm{~s}\right.$ at $\left.4^{\circ} \mathrm{C}\right)$ and protein concentrations were determined using a "Coomassie Plus - The Better Bradford Assay" Kit (Thermo Scientific ${ }^{\circledR}$ ). For the P-gp positive control, a trout liver extract treated under the same conditions was also used $^{23}$. Western blot analysis was then carried out according to Vaché et al., $2006^{12}$ Briefly, for each analysis, extracts were diluted to $100 \mu \mathrm{g} \cdot \mathrm{ml}^{-1}$ protein with sample buffer (1.25 M tris- $\mathrm{HCl}, 20 \%$ sodium dodecyl sulfate, $20 \%$ glycerol, $2 \mathrm{M}$ dithiothreitol, $0.5 \%$ bromophenol blue, $\mathrm{pH}$ 6.8). For these experiments, the primary monoclonal antibody anti-P-gp C219 (1:500, Calbiochem $\left.{ }^{\circledR}\right)$, the mouse monoclonal antitubulin antibody DM1A $\left(1: 5000\right.$, Sigma $\left.{ }^{\circledR}\right)$ and the secondary antibody, a horseradish-peroxidase (HRP)-coupled goat anti-mouse $\left(1: 4000\right.$, Promega $\left.{ }^{\circledR}\right)$ were used. Immune complexes were visualized by chemiluminescence (ECL + Western blotting detection reagent, Amersham ${ }^{\circledR}$ ) according to the manufacturer's specifications. The intensities of P-gp and control tubulin bands were analyzed by densitometry using Quantity-One software (BioRad ${ }^{\circledR}$ ). For each sample, P-gp expression was determined by calculating the ratio of the density of each MDR protein over the density of the tubulin control. This ratio was expressed in arbitrary units (a.u.)

Statistical analysis. Data were expressed as means \pm confidence intervals of $n$ independent experiments. Each experiment was performed at least in triplicate and then statistically compared using ANOVA and a Student's t-test. The comparison was applied on each culture condition and on control groups versus $\mathrm{B} a \mathrm{P}$-treated groups and $\mathrm{P}<0.05$ was considered statistically significant.

1. Soldatov, A. Red blood system in fish: peculiarities of its organisation and function. Zh Evol Biokhim Fiziol 41, 217-223 (2005)

2. Mortensen, A. S., Letcher, R. J., Cangialosi, M. V., Chu, S. \& Arukwe, A. Tissue bioaccumulation patterns, xenobiotic biotransformation and steroid hormone levels in Atlantic salmon (Salmo salar) fed a diet containing perfluoroactane sulfonic or perfluorooctane carboxylic acids. Chemosphere 83, 1035-1044, DOI:10.1016/j.chemosphere.2011.01.067 (2011).

3. Sarkadi, B., Homolya, L., Szakacs, G. \& Varadi, A. Human multidrug resistance $\mathrm{ABCB}$ and $\mathrm{ABCG}$ transporters: participation in a chemoimmunity defense system. Physiol Rev 86, 1179-1236, DOI:10.1152/physrev.00037.2005 (2006). 
4. Gerlach, J. H. et al. Homology between P-glycoprotein and a bacterial haemolysin transport protein suggests a model for multidrug resistance. Nature 324, 485-489, DOI:10.1038/324485a0 (1986).

5. Bamdad, M., Brousseau, P. \& Denizeau, F. Identification of a multidrug resistance-like system in Tetrahymena pyriformis: evidence for a new detoxication mechanism in freshwater ciliates. FEBS Lett 456, 389-393, DOI:S00145793(99)00978-3 (1999).

6. Bamdad, M., Reader, S., Grolière, C. A., Bohatier, J. \& Denizeau, F. Uptake and efflux of polycyclic aromatic hydrocarbons by "Tetrahymena pyriformis": Evidence for a resistance mechanism. Cytometry 28, 170-175 (1997).

7. Fischer, S. et al. Constitutive mRNA expression and protein activity levels of nine $\mathrm{ABC}$ efflux transporters in seven permanent cell lines derived from different tissues of rainbow trout (Oncorhynchus mykiss). Aquat Toxicol 101, 438-446, DOI:10.1016/j.aquatox.2010.11.010 (2011).

8. Kurelec, B. The multixenobiotic resistance mechanism in aquatic organisms. Crit Rev Toxicol 22, 23-43, DOI:10.3109/10408449209145320 (1992).

9. Loncar, J., Popovic, M., Zaja, R. \& Smital, T. Gene expression analysis of the ABC efflux transporters in rainbow trout (Oncorhynchus mykiss). Comp Biochem Physiol C. Toxicol Pharmacol 151, 209-215, DOI:10.1016/j.cbpc.2009.10.009 (2010).

10. Sturm, A., Cravedi, J. P. \& Segner, H. Prochloraz and nonylphenol diethoxylate inhibit an mdr1-like activity in vitro, but do not alter hepatic levels of Pglycoprotein in trout exposed in vivo. Aquat Toxicol 53, 215-228 (2001).

11. Vache, C. et al. A potential genomic biomarker for the detection of polycyclic aromatic hydrocarbon pollutants: multidrug resistance gene 49 in Drosophila melanogaster. Environ Toxicol Chem 26, 1418-1424 (2007).

12. Vache, C. et al. Drosophila melanogaster p-glycoprotein: a membrane detoxification system toward polycyclic aromatic hydrocarbon pollutants. Environ Toxicol Chem 25, 572-580 (2006).

13. Zaja, R., Klobucar, R. S. \& Smital, T. Detection and functional characterization of Pgp1 (ABCB1) and MRP3 (ABCC3) efflux transporters in the PLHC-1 fish hepatoma cell line. Aquat Toxicol 81, 365-376 (2007).

14. Agarwala, S., Chen, W. \& Cook, T. J. Effect of chlorpyrifos on efflux transporter gene expression and function in Caco-2 cells. Toxicol In Vitro 18, 403-409, DOI:10.1016/j.tiv.2003.12.006 (2004).

15. Bard, S. M. Multixenobiotic resistance as a cellular defense mechanism in aquatic organisms. Aquat Toxicol 48, 357-389, DOI:S0166-445X(00)00088-6 (2000).

16. Einicker-Lamas, M. et al. P-glycoprotein-like protein contributes to cadmium resistance in Euglena gracilis. J Comp Physiol B 173, 559-564, DOI:10.1007/ s00360-003-0365-5 (2003).

17. Habibollahi, P., Ghahremani, M. H., Azizi, E. \& Ostad, S. N. Multi drug resistance1 (MDR1) expression in response to chronic diazinon exposure: an in vitro study on Caco-2 cells. Bull Environ Contam Toxicol 86, 105-109, DOI:10.1007/s00128010-0158-y (2011).

18. Marquez B, V. B. F. ABC multidrug transporters: target for modulation of drug pharmacokinetics and drug-drug interactions. Curr Drug Targets 12, 600-620 (2011).

19. Prevodnik, A., Lilja, K. \& Bollner, T. Benzo[a]pyrene up-regulates the expression of the proliferating cell nuclear antigen (PCNA) and multixenobiotic resistance polyglycoprotein (P-gp) in Baltic Sea blue mussels (Mytilus edulis L.). Comp Biochem Physiol C Toxicol Pharmacol 145, 265-274, DOI:10.1016/ j.cbpc.2006.12.014 (2007).

20. Shabbir, A. et al. Differential effects of the organochlorine pesticide DDT and its metabolite $\mathrm{p}, \mathrm{p}^{\prime}$-DDE on $\mathrm{p}$-glycoprotein activity and expression. Toxicol Appl Pharmacol 203, 91-98, DOI:10.1016/j.taap.2004.07.011 (2005).

21. Sugihara, N. et al. Effects of benzo(e)pyrene and benzo(a)pyrene on Pglycoprotein-mediated transport in Caco-2 cell monolayer: a comparative approach. Toxicol In Vitro 21, 827-834, DOI:10.1016/j.tiv.2007.02.005 (2007).

22. Urayama, K. Y. et al. MDR1 gene variants, indoor insecticide exposure, and the risk of childhood acute lymphoblastic leukemia. Cancer Epidemiol Biomarkers Prev 16, 1172-1177, DOI:10.1158/1055-9965.EPI-07-0007 (2007).
23. Sturm, A., Ziemann, C., Hirsch-Ernst, K. I. \& Segner, H. Expression and functional activity of P-glycoprotein in cultured hepatocytes from Oncorhynchus mykiss. Am J Physiol Regul Integr Comp Physiol 281, R1119-1126 (2001).

24. Van Den Elsen, J. M., Kuntz, D. A., Hoedemaeker, F. J. \& Rose, D. R. Antibody C219 recognizes an alpha-helical epitope on P-glycoprotein. Proc Natl Acad Sci U S A 96, 13679-13684 (1999).

25. Fardel, O., Lecureur, V., Corlu, A. \& Guillouzo, A. P-glycoprotein induction in rat liver epithelial cells in response to acute 3-methylcholanthrene treatment. Biochem Pharmacol 51, 1427-1436 (1996).

26. Ikenaka, Y. et al. Effects of polycyclic aromatic hydrocarbons (PAHs) on an aquatic ecosystem: acute toxicity and community-level toxic impact tests of benzo[a]pyrene using lake zooplankton community. J Toxicol Sci 38, 131-136 (2013).

27. Song, M. K. et al. Formation of a 3,4-diol-1,2-epoxide metabolite of benz[a] anthracene with cytotoxicity and genotoxicity in a human in vitro hepatocyte culture system. Environ Toxicol Pharmacol 33, 212-225, DOI:10.1016/j.etap.2011.12.020 (2012).

28. Topinka, J. et al. DNA adducts formation and induction of apoptosis in rat liver epithelial 'stem-like' cells exposed to carcinogenic polycyclic aromatic hydrocarbons. Mutat Res 638, 122-132, DOI:10.1016/j.mrfmmm.2007.09.004 (2008).

29. Lampen, A., Ebert, B., Stumkat, L., Jacob, J. \& Seidel, A. Induction of gene expression of xenobiotic metabolism enzymes and $\mathrm{ABC}$-transport proteins by PAH and a reconstituted PAH mixture in human Caco-2 cells. Biochim Biophys Acta 1681, 38-46, DOI:10.1016/j.bbaexp.2004.09.010 (2004).

30. Germann, U. A. P-glycoprotein--a mediator of multidrug resistance in tumour cells. Eur J Cancer 32A, 927-944 (1996).

31. Beaulieu, E. et al. P-glycoprotein of blood brain barrier: cross-reactivity of Mab C219 with a $190 \mathrm{kDa}$ protein in bovine and rat isolated brain capillaries. Biochim Biophys Acta 1233, 27-32 (1995).

32. Ao, J., Ruan, X., Yan, Y. \& Cai, M. Distribution, sources and ecological risks of polycyclic aromatic hydrocarbons in an urban landscape river. Water Sci Technol 66, 934-941, DOI:10.2166/wst.2012.248 (2012).

33. Zhong, Y. \& Zhu, L. Distribution, input pathway and soil-air exchange of polycyclic aromatic hydrocarbons in Banshan Industry Park, China. Sci Total Environ 444, 177-182, DOI:10.1016/j.scitotenv.2012.11.091 (2013).

\section{Acknowledgments}

This work was funded by grants from the Regional Council of Auvergne and European Regional Development Fund. The authors wish to express their gratitude to Fabrice Kwiatkowski for statistical analysis and helpful discussion.

\section{Author contributions}

E.V. executed the experiments. E.V. and M.B. wrote the main manuscript text. E.V. and I.W. prepared figures 1-4. All authors read and approved the final manuscript.

\section{Additional information}

Supplementary information accompanies this paper at http://www.nature.com/ scientificreports

Competing financial interests: The authors declare no competing financial interests. How to cite this article: Valton, E., Amblard, C., Wawrzyniak, I., Penault-Llorca, F. \& Bamdad, M. P-gp expression in brown trout erythrocytes: evidence of a detoxification mechanism in fish erythrocytes. Sci. Rep. 3, 3422; DOI:10.1038/srep03422 (2013).

(i) (2) This work is licensed under a Creative Commons AttributionBY NG SA NonCommercial-ShareAlike 3.0 Unported license. To view a copy of this license, visit http://creativecommons.org/licenses/by-nc-sa/3.0 